\title{
ISSN $1684-8853$
}

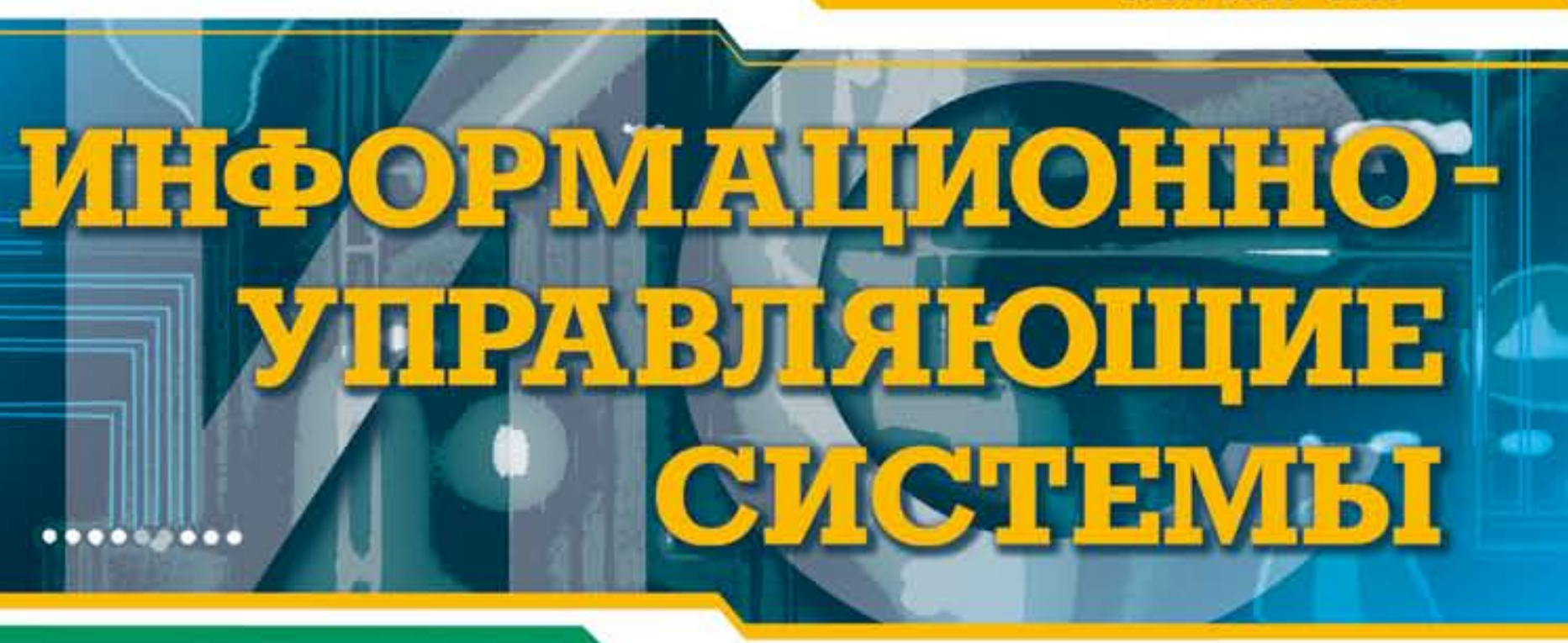

НАУЧНЫЙ ЖУРНАЛ

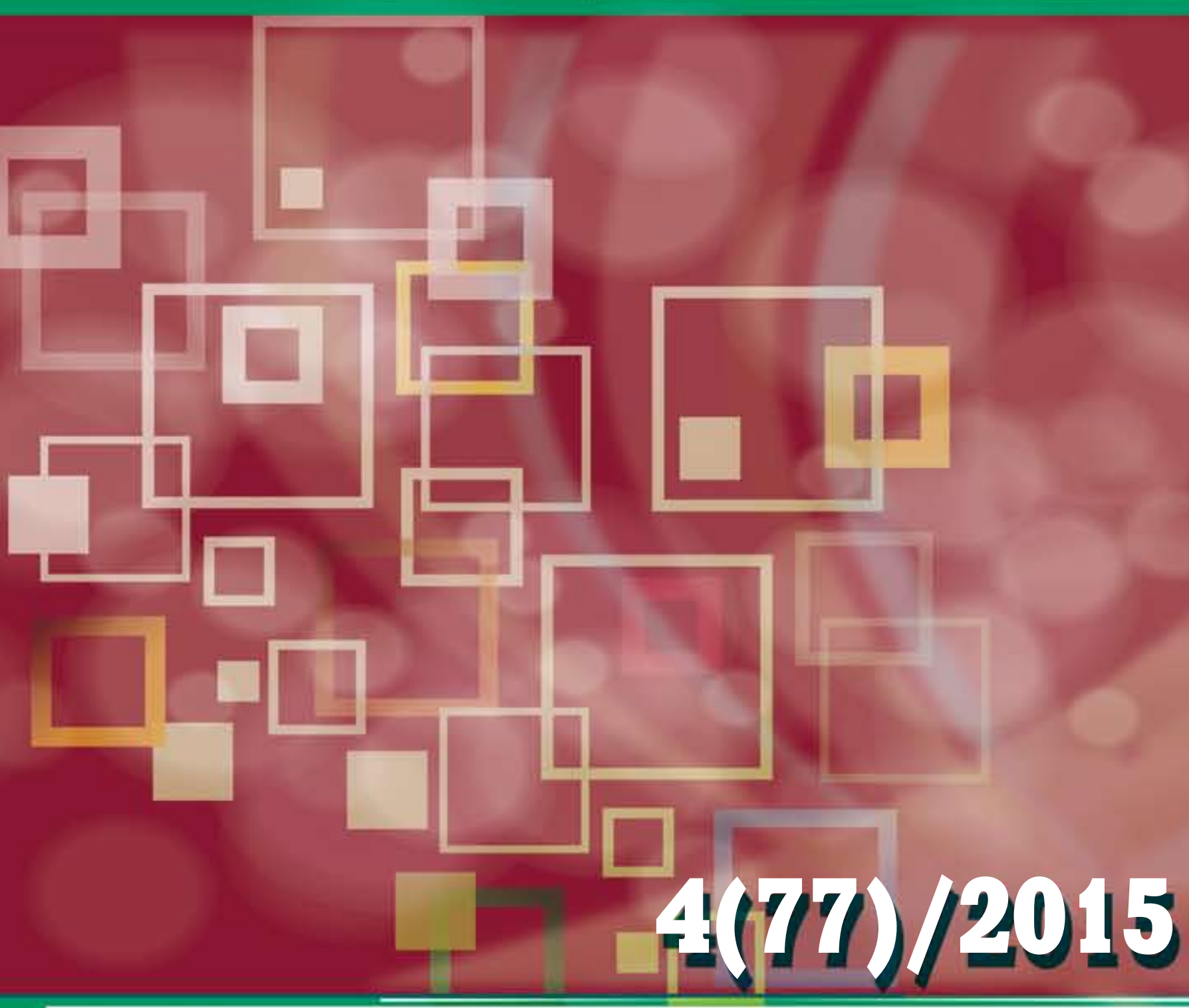

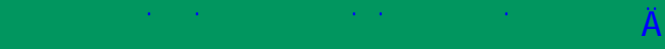




\section{$4(77) / 2015$}

INFORMATSIONNOUPRAVLIAIUSHCHIE SISTEMY

\section{REFEREED EDITION}

(INFORMATION

AND CONTROL SYSTEMS)

Founder

«Information and Control Systems», Ltd.

Publisher

Saint-Petersburg State University

of Aerospace Instrumentation

Editor-in-Chief

M. Sergeev
Dr. Sc., Tech., Professor, St. Petersburg, Russia

Deputy Editor-in-Chief

E. Krouk

Dr. Sc., Tech., Professor, St. Petersburg, Russia

Executive secretary

O. Muravtsova

Editorial Council

C. Christodoulou

PhD, Professor

L. Chubraeva

RAS Corr. Member, Dr. Sc., Tech., Professor, St. Petersburg, Russia

L. Fortuna

PhD, Professor, Catania, Italy

A. Fradkov

Dr. Sc., Tech., Professor, St. Petersburg, Russia

V. Kozlov

B. Meye

Dr. Sc., Professor, Zurich, Switzerland

A. Ovodenko

Dr. Sc., Tech., Professor, St. Petersburg, Russia

Y. Podoplyokin

Dr. Sc., Tech., Professor, St. Petersburg, Russia

Yu. Shokin

V. Simakov

Dr. Sc., Tech., Professor, Moscow, Russia

V. Vasilev

RAS Corr. Member, Dr. Sc., Tech., Professor, St. Petersburg, Russia R. Yusupov

RAS Corr. Member, Dr. Sc., Tech., Professor, St. Petersburg, Russia

Editorial Board

V. Anisimov

Dr. Sc., Tech., Professor, St. Petersburg, Russia

B. Bezruchko

Dr. Sc., Phys.-Math., Saratov, Russia

Dr. Sc., Phys.-Math., Professor, Beer-Sheva, Israel

A. Dudin

A. Dudin

I. Dumer

PhD., Professor, Riverside, USA

V. Khimenko

G. Maltsev
Dr. Sc., Tech, Professor, St. Petersburg, Russia

V. Melekhin
Dr. Sc., Tech., Professor, St. Petersburg, Russia

A. Shalyto
Dr. Sc., Tech., Professor, St. Petersburg, Russia

A. Shepeta
Dr. Sc., Tech., Professor, St. Petersburg, Russia

A. Smirnov

Dr. Sc., Tech., Professor, St. Petersburg, Russia

Z. Yuldashev

Dr. Sc., Tech., Professor, St. Petersburg, Russia

Dr. Sc., Phys.-Math., Vologda, Russia

Editor: A. Larionova

Proofreader: T. Zvertanovskaia

Design: N. Karavaeva, M. Chernenko

Layout and composition: N. Karavaeva

Contact information

The Editorial and Publishing Center, SUA

67, B. Morskaia, 190000, St. Petersburg, Russia

Website: http://i-us.ru/en, E-mail: ius.spb@gmail.com
Tel.: +7 - 8124947002

INFORMATION PROCESSING AND CONTROL

Kostoglotov A. A., Kuznetsov A. A., Lazarenko S. V., Losev V. A. Synthesis of Filter Support with Structural Adaptation Based on Combined Maximum Principle

INFORMATION PROCESSING AND CONTROL

Lakhin O. I., Simonova E. V., Skobelev P. O., Polnikov A. S., Yurygina Y. S. Developing a Prototype Intelligent System for Maintenance and Repair of Aerospace Products Based on Multi-Agent Technologies

SYSTEM AND PROCESS MODELING

Balonin N. A. Discrete Frequency Characteristics of Elementary

Dynamic Units

Zharinov I. O., Zharinov O. O. Model of an Automatic Control System for

Thermal Conditions of an LCD Panel in On-board Indication Equipment

Kiselev V. Y., Monakov A. A. Aircraft Trajectory Prediction in Air Traffic

Control Systems

Dushin S. E., Abramkin S. E. Mathematical Modeling of Controlled

Processes of Natural Gas Dehydration

Khomonenko A. D., Danilov A. I., Danilov A. A. Non-stationary Models

of Software Testing Strategies with Probabilistic Parameters

for Fault Detection

Grudyaeva E. K. Synthesizing a Control System for Removing Nitrogen Compounds from Wastewater

\section{INFORMATION SECURITY}

Branitskiy A A., Kotenko I. V. Network Attack Detection Based on Combination of Neural, Immune and Neuro-fuzzy Classifiers

INFORMATION CHANNELS AND MEDIUM

Maltsev G. N., Sakulin A. N. Statistical Characteristics of Accelerated

Delay-Based Search of Signals Using Pseudorandom Sequences with Locally Optimal Correlation Properties

Abramov A. P., Petrov P. N. Device to Determine the Phase Structure of a Radio Signal

Kaliuzhnuy V. P. Stability of Digital Regulators with Network Delivery of Controlling Variables

Bakin E. A., Apanasenko N. V. Evaluation of PPM IR-UWB Resistance to Impulse Interference at High Signal-to-Noise Ratio

\section{INFORMATION SECURITY}

Melnikov Y. P. Assessing the Efficiency of Using Multipath Signals of an "Outside» Radar for Covert Determination of Coordinates of Ships and Aircrafts

Arseniev V. N., Trofimov I. A. Solving the Choice Problem in the Conditions of Physical Diversity and Limited Observable Signs

\section{BRIEF SCIENTIFIC REPORTS}

Ziatdinov S. I. Synthesis of the Differentiated Filter with Linear Frequency Characteristic

CHRONICLES AND INFORMATION

On the Centenary of the Birth of Victor A. Besekersky

INFORMATION ABOUT THE AUTHORS

\footnotetext{
Submitted for publication 03.07.15. Passed for printing 24.08.15. Format $60 \times 84_{1 / 8}$. Offset paper. Phototype SchoolBookC. Offset printing.

Layout original is made at the Editorial and Publishing Center, SUAI.

Printed from slides at the Editorial and Publishing Center, SUAl.

67, B. Morskaia, 190000, St. Petersburg, Russia
}

The journal is distributed by subscription. Subscription can be made in the Editorial and publishing № 48060 - a a in any post office based on "Rospechat" catalogue: 


\section{$4(77) / 2015$}

ИНФОРМАЦИОННОУПРАВЛЯЮЩИЕ

РЕЦЕНЗИРУЕМОЕ ИЗДАНИЕ CИСТЕМЫ

Учредитель

ООО «Информационно-управляющие системы»

Издатель

Санкт-Петербургский государственный университет

аэрокосмического приборостроения

Главный редактор

М. Б. Сергеев,

д-р техн. наук, проф., С.-Петербург, РФ

Зам. главного редактора

Е. А. Крук,
д-р техн. наук, проф., С.-Петербург, РФ

Ответственный секретарь

О. В. Муравцова

Редакционный совет:

Председатель А. А. Оводенко,

д-р техн. наук, проф., С.-Петербург, РФ

В. Н. Васильев,

чл.-корр. РАН, д-р техн. наук, проф., С.-Петербург, РФ

В. Н. Козлов,

д-р техн. наук, проф., С.-Петербург, РФ

К. Кристодолу,

д-р наук, проф., Альбукерке, Нью-Мексико, США

Б. Мейер,

д-р наук, проф., Цюрих, Швейцария

Ю. Ф. Подоплёкин,

д-р техн. наук, проф., С.-Петербург, РФ

В. В. Симаков,

д-р техн. наук, проф., Москва, РФ

Л. Фортуна,

д-р наук, проф., Катания, Италия

А. Л. Фрадков

д-р техн. наук, проф., С.-Петербург, РФ

Л. И. Чубраева,

чл.-корр. РАН, д-р техн. наук, С.-Петербург, РФ

Юкад. РАН, д-р физ.-мат. наук, проф., Новосибирск, РФ

Р. М. Юсупов,

Редакционная коллегия:

В. Г. Анисимов,

д-р техн. наук, проф., С.-Петербург, РФ

Б. П. Безручко,

д-р физ.-мат. наук, проф., Саратов, РФ

Н. Блаунштейн,

д-р физ.-мат. наук, проф., Беэр-Шева, Израиль

д. А. Ф. Дудин

д-р физ.-мат. наук, проф., Минск, Беларусь

И. И. Думер,

д-р наук, проф., Риверсайд, США

А. И. Зейфман,

д-р физ.-мат. наук, проф., Вологда, РФ

Г. Н. Мальцев,

д-р техн. наук, проф., С.-Петербург, РФ

В. Ф. Мелехин,

д-р техн. наук, проф., С.-Петербург, РФ

А. В. Смирнов

д-р техн. наук, проф., С.-Петербург, РФ

В.И. Хименко,

д-р техн. наук, проф., С.-Петербург, РФ

А. А. Шалыто,

д-р техн. наук, проф., С.-Петербург, РФ

А. П. Шепета,

д-р техн. наук, проф., С.-Петербург, РФ

3. М. Юлдашев

д-р техн. наук, проф., С.-Петербург, РФ

Редактор: А. Г. Ларионова

Корректор: Т. В. Звертановская

Дизайн: Н. Н. Караваева, М. Л. Черненко

Компьютерная верстка: Н. Н. Караваева

Адрес редакции: 190000, Санкт-Петербург,

Б. Морская ул., Д. 67, ГУАП, РИЦ

Тел.: (812) 494-70-02, e-mail: ius.spb@gmail.com, сайт: http://i-us.ru

Журнал зарегистрирован в Министерстве РФ по делам печати,

телерадиовещания и средств массовых коммуникаций

Твлериовещания о сртрации ПИ № 77-12412 от 19 апреля 2002 г.
Перерегистрирован в Роскомнадзоре.

Свидетельство о регистрации ПИ № ФС77-49181 от 30 марта 2012 г.

Журнал входит в «Перечень ведущих рецензируемых научных журналов и изданий,

в которых должны быть опубликованы основные научные результаты диссертации

на соискание ученой степени доктора и кандидата наук».

๑ Коллектив авторов, 2015

ОБРАБОТКА ИНФОРМАЦИИ И УПРАВЛЕНИЕ

Костоглотов А. А., Кузнецов А. А., Лазаренко С. В., Лосев В. А.

Синтез фильтра сопровождения со структурной адаптацией

на основе объединенного принципа максимума

ИНФОРМАЦИОННО-УПРАВЛЯЮЩИЕ СИСТЕМЬ

Лахин О. И., Симонова Е. В., Скобелев П. О., Полников А. С.,

Юрыгина Ю. С. Подход к разработке прототипа интеллектуальной

системы поддержки процессов технического обслуживания и ремонта при эксплуатации изделий аэрокосмической промышленности

на основе мультиагентных технологий

МОДЕЛИРОВАНИЕ СИСТЕМ И ПРОЦЕССОВ

Балонин Н. А. Дискретные частотные характеристики

элементарных динамических звеньев

Жаринов И. О., Жаринов О. О. Модель системы автоматического

управления тепловым режимом жидкокристаллической панели

бортового средства индикации

Киселев В. Ю., Монаков А. А. Предсказание траектории

воздушного судна в автоматизированных системах управления

воздушным движением

Душин С. Е., Абрамкин С. Е. Математическое моделирование

управляемых технологических процессов осушки природного газа

Хомоненко А. Д., Данилов А. И., Данилов А. А. Нестационарные

модели стратегий испытаний программных средств

при вероятностных параметрах обнаружения ошибок

Грудяева Е. К. Синтез системы управления технологическим

процессом удаления соединений азота из сточных вод

\section{ЗАЩИТА ИНФОРМАЦИИ}

Браницкий А. А., Котенко И. В. Обнаружение сетевых атак на основе комплексирования нейронных, иммунных

и нейронечетких классификаторов

ИНФОРМАЦИОННЫЕ КАНАЛЫ И СРЕДЫ

Мальцев Г. Н., Сакулин А. Н. Статистические характеристики

ускоренного поиска сигналов по задержке с использованием

псевдослучайных последовательностей с локально оптимальными

корреляционными свойствами

Абрамов А. П., Петров П. Н. УСтройство определения

фазовой структуры радиосигнала

Калюжный В. П. Проблема устойчивости цифровых регуляторов

с сетевым способом доставки управляющих величин

Бакин Е. А., Апанасенко Н. В. Анализ устойчивости системь

с позиционно-импульсной модуляцией к воздействию ХИП

при высоких отношениях сигнал/шум

ИНФОРМАЦИОННО-ИЗМЕРИТЕЛЬНЫЕ СИСТЕМЫ

Мельников Ю. П. Особенности методики оценки эффективности

применения переотраженных сигналов «посторонней» РЛС

для скрытного определения координат кораблей

и летательных аппаратов

Арсеньев В. Н., Трофимов И. А. Решение задачи выбора

в условиях физической неоднородности и ограниченности наблюдаемых признаков

КРАТКИЕ СООБЩЕНИЯ

Зиатдинов С. И. Синтез дифференцирующего фильтра с линейной

частотной характеристикой

ХРОНИКА И ИНФОРМАЦИЯ

К 100-летию со дня рождения Виктора Антоновича Бесекерского

СВЕДЕНИЯ ОБ АВТОРАХ

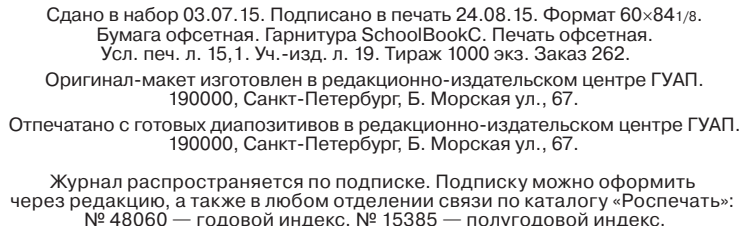

дано в набор 03.07.15. Подписано в печать 24.08.15. Формат 60×841/8.

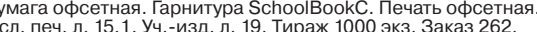
190000, Санкт-Петербург, Б. Морская ул., 67.
Изговон 190000, Санкт-Петербург, Б. Морская ул., 67.

№ 48060 - годовой индекс, № 15385 - полугодовой индекс. 